\title{
HYDROTHERMAL SYNTHESIS AND CHARACTERISATION OF AMINE-TEMPLATED METAL PHOSPHATE FRAMEWORK
}

\author{
JOSEPH G. ATAI, SAMUEL S. ETUK AND AYI A. AYI
}

(Received 15 January 2014; Revision Accepted 14 March 2014)

\begin{abstract}
Two coordination polymers $\left[\mathrm{CH}_{3} \mathrm{CH}_{2} \mathrm{NH}_{3}\right]_{2} \mathrm{M}_{3}\left(\mathrm{NH}_{3} \mathrm{C}_{6} \mathrm{H}_{4} \mathrm{CO}_{2}\right)_{2}\left(\mathrm{HPO}_{4}\right)_{4}\left(\mathrm{H}_{2} \mathrm{O}\right)_{2}(\mathrm{M}=\mathrm{Ni}$ for compound $\mathrm{I}$ and $\mathrm{M}=\mathrm{Zn}$ for compound II) incorporating ethylammonium-4-aminobenzoate, were hydrothermally synthesized (autogeneous pressure for 5 days) at $105^{\circ} \mathrm{C}$. The Scanning Electron Micrographs revealed a greenish rectangular block for the $\mathrm{Ni}(\mathrm{II})$ complex and a colourless square plate for the $\mathrm{Zn}$ (II) complex. The complexes were characterised by IR-spectroscopy and the Infrared spectra of the two compounds exhibited similar essential features. The Spectra clearly showed the presence of co-ordinated water and terminal $-\mathrm{NH}_{3}{ }^{+}$. The broad band at $3914 \mathrm{~cm}^{-1}$ (I) and $3926-3760 \mathrm{~cm}^{-1}$ (II) is due to the presence of water molecule in the structure. The bands at $3542-3401 \mathrm{~cm}^{-1}$ (I) and $3434 \mathrm{~cm}^{-1}$ are associated with stretching vibration of $v\left(-\mathrm{NH}_{2}\right)$. The strong absorption bands at $1108-1014 \mathrm{~cm}^{-1}$ (I) and $1108-1018 \mathrm{~cm}^{-1}$ (II) are associated with the asymmetric stretching vibration of $v\left(\mathrm{PO}_{4}\right)$ groups, whereas those at $936-629 \mathrm{~cm}^{-1}(\mathrm{I})$ and $934-$ $718 \mathrm{~cm}^{-1}$ (II) correspond to its bending mode. The complexes were thermally stable up to $300^{\circ} \mathrm{C}$, after which the organic components starts decomposing. The solubility test in a wide spectrum of solvents (at room temperature) showed that the complexes were insoluble in water, ethanol, DMF and DMSO.
\end{abstract}

KEYWORDS: Hydrothermal synthesis, metal phosphates, p-aminobenzoic acid, ethylacetoacetate, ethylammonium4-aminobenzoate.

\section{INTRODUCTION}

One of the major areas of materials science is the development of solid state materials with extended structures that have empty spaces between their components, such as porous (Rowsell and Yaghi, 2004), layered (Logar et al., 2005), or one-, two-, or threedimensional compounds (Chen et al., 2008). The presence of pores, inter-layer or inter-chain spaces allows for many applications of these materials. A metalorganic framework (MOF) is composed of two major components: a metal ion or cluster of metal ions and an organic molecule called a linker. The organic units are typically mono-, di-, tri-, or tetravalent ligands (Czaja, Trukhan and Muller, 2009). Transition metal ions are often used as versatile connectors in the construction of MOFs. The first row transition metal ions such as $\mathrm{Zn}^{2+}$, $\mathrm{Co}^{2+}, \mathrm{Cd}^{2+}, \mathrm{Fe}^{2+}$ are especially commonly used (Ayi, Choudhury and Rao, 2005; Natarajan et al., 2006). Some alkaline metal ions (Ayi et al., 2011), alkaline earth metal ions (Murugavel et al., 2000) and rare earth metal ions (Clearfield and Demadis, 2012) have also been employed as metal nodes for constructing MOF structures.

The important characteristics of metal connectors are the number and orientation of their building sites (coordination numbers and coordination geometries). Depending on the metal and its oxidation state, coordination numbers can range from 2 to 7 , giving rise to various geometries such as linear, $\mathrm{T}$ - or $\mathrm{Y}$ - shaped, square-planar, tetrahedral, square pyramidal, octahedral etc, which play an important role in directing the MOF structures (Kitagawa, Kitaura and Noro, 2004). The ligands used in the construction of coordination polymers have to bridge between metal ions. This requires usually multidentate ligands with two or more donor atoms. Such bridging ligands are called di-, tri-, tetratopic depending on the number of donor atoms. Of special importance are rigid bridging ligands since they allow for a certain control of the steric consequences in the assembly process (Halper et al., 2006).

Hydrothermal synthesis is currently one of the principal methods of synthesis for the preparation of new inorganic materials. It involves the heating of solid and liquid reagents with a suitable solvent (usually water) in a sealed vessel called autoclave at temperature above the boiling point of the liquid and up to $250^{\circ} \mathrm{C}$ and requires a long reaction time (days to weeks).

This paper reports hydrothermal synthesis and spectral characterisation of two metal phosphates incorporating ethylammonium ion.

\section{EXPERIMENTAL}

Synthesis of Ethyl ammonium bis(4-carboxyphenyl) amino $\mathrm{Ni}(\mathrm{II})$ dihydrogen phosphate $\left[\mathrm{CH}_{3} \mathrm{CH}_{2} \mathrm{NH}_{3}\right]_{2} \mathrm{Ni}_{3}\left(\mathrm{NH}_{3} \mathrm{C}_{6} \mathrm{H}_{4} \mathrm{CO}_{2}\right)_{2}\left(\mathrm{HPO}_{4}\right)_{4}\left(\mathrm{H}_{2} \mathrm{O}\right)_{2}-\mathrm{I}$

The resultant mixture with molar composition $3 \mathrm{C}_{2} \mathrm{H}_{5} \mathrm{NH}_{2}$ $+2 \mathrm{NH}_{2} \mathrm{C}_{6} \mathrm{H}_{4} \mathrm{COOH}+3 \mathrm{H}_{3} \mathrm{PO}_{4}+3 \mathrm{CH}_{3} \mathrm{COCH}_{2} \mathrm{CO}_{2} \mathrm{C}_{2} \mathrm{H}_{5}+$ $278 \mathrm{H}_{2} \mathrm{O}+3 \mathrm{NiCl}_{2} \cdot 6 \mathrm{H}_{2} \mathrm{O}$

Joseph G. Atai, Department of Pure and Applied Chemistry, University of Calabar, Calabar, Cross River State, Nigeria.

Samuel S. Etuk, Department of Pure and Applied Chemistry, University of Calabar, Calabar, Cross River State, Nigeria.

Ayi A. Ayi, Department of Pure and Applied Chemistry, University of Calabar, Calabar, Cross River State, Nigeria. 


\section{Procedure}

In the synthesis of compound $\mathrm{I}, 1.785 \mathrm{~g}$ of $\mathrm{NiCl}_{2} \cdot 6 \mathrm{H}_{2} \mathrm{O}$ was dissolved in $5 \mathrm{ml}$ of distilled water and poured into $50 \mathrm{ml}$ beaker. To the solution, $0.5 \mathrm{ml}$ of $\mathrm{H}_{3} \mathrm{PO}_{4}$ was added under effective stirring for 7 minutes before $1 \mathrm{ml}$ of ethylacetoacetate, $0.5 \mathrm{ml}$ of $\mathrm{C}_{2} \mathrm{H}_{5} \mathrm{NH}_{2}$ and $0.685 \mathrm{~g}$ of $\mathrm{p}$ aminobenzoic acid were added and stirred for 30 minutes for complete homogeneity. The resultant mixture with $\mathrm{pH}$ of 4 was sealed in a $37 \mathrm{ml}$ Teflon lined stainless steel autoclave and kept at $105^{\circ} \mathrm{C}$ for 5 days. The greenish crystals obtained were washed, filtered and dried at ambient temperature. The synthesized compound was characterized by melting point, solubility in different solvents and infrared spectroscopy.

Synthesis of Ethyl ammonium bis(4-carboxyphenyl)
amino $\mathrm{Zn}(\mathrm{II})$ dihydrogen phosphate
$\left[\mathrm{CH}_{3} \mathrm{CH}_{2} \mathrm{NH}_{3}\right]_{2} \mathrm{Zn}_{3}\left(\mathrm{NH}_{3} \mathrm{C}_{6} \mathrm{H}_{4} \mathrm{CO}_{2}\right)_{2}\left(\mathrm{HPO}_{4}\right)_{4}\left(\mathrm{H}_{2} \mathrm{O}\right)_{2}$ - II

Composition of reaction

$2 \mathrm{ZnO}+3 \mathrm{C}_{2} \mathrm{H}_{5} \mathrm{NH}_{2}+2 \mathrm{NH}_{2} \mathrm{C}_{6} \mathrm{H}_{4} \mathrm{COOH}+3 \mathrm{H}_{3} \mathrm{PO}_{4}+3 \mathrm{HCl}$ $+222 \mathrm{H}_{2} \mathrm{O}$

\section{Procedure}

In the synthesis of compound II, $0.367 \mathrm{~g}$ of $\mathrm{ZnO}$ was dispersed in $8 \mathrm{ml}$ of distilled water in a $50 \mathrm{ml}$ beaker. $0.6 \mathrm{ml}$ of conc. $\mathrm{HCl}$ was added to the solution as a mineralizing agent and the mixture was stirred for 7 minutes. To the mixture, $0.3 \mathrm{ml}$ of $\mathrm{H}_{3} \mathrm{PO}_{4}$ was added under effective stirring for 7 minutes before $0.3 \mathrm{ml}$ of $\mathrm{C}_{2} \mathrm{H}_{5} \mathrm{NH}_{2}$ and $0.411 \mathrm{~g}$ of $\mathrm{p}$-aminobenzoic acid was added and stirred for 30 minutes for complete homogeneity. The resultant mixture with $\mathrm{pH}$ of 4 was sealed in a $13 \mathrm{ml}$ Teflon lined stainless steel autoclave and kept at $105^{\circ} \mathrm{C}$ for 5 days. The colourless single crystals obtained was washed, filtered and dried at ambient temperature. The synthesized compound was characterized by melting point, solubility in different solvents and infrared spectroscopy.

\section{Characterization}

Infrared spectroscopy (IR)

The Fourier Transform Infrared (FTIR) spectra of the compounds under investigation were recorded between $4000-350 \mathrm{~cm}^{-1}$ on Perkin Elmer FTIR spectrophotometer. The compounds were prepared on $\mathrm{KBr}$ disc at the Multidisciplinary Central Research Laboratory, University of Ibadan.

\section{Melting point determination}

The melting points of the compounds were measured using melting point apparatus $\left(\mathrm{SMP}_{3}\right.$ Biocote) and capillary tube. The capillary tube was sealed at one end and the sample was introduced through the open end of the tube. The samples in the tubes were inserted into the melting point instrument and the temperature at which the substances melted was noted.

\section{$\mathrm{pH}$ determination}

The $\mathrm{pH}$ of the reaction medium was measured using $\mathrm{pH}$ paper

\section{Solubility determination}

The solubility test of compound I and II were determined in water, ethanol, dimethylformamide (DMF) and dimethylsulphoxide (DMSO) at room temperature.

\section{Elemental Composition}

The elemental compositions of compounds I and II were obtained from the proposed structures. The percentage yields of the compounds were low, and as such, there were not enough samples for XRF analysis.

\section{RESULTS AND DISCUSSIONS}

The $\mathrm{Ni}(\mathrm{II}) \quad \mathrm{I}$, and $\mathrm{Zn}(\mathrm{II}) \quad \mathrm{II}$; phosphates incorporating ethylammonium-4-aminobenzoate, were hydrothermally synthesized (autogeneous pressure for 5 days) at $105^{\circ} \mathrm{C}$. A pH value of 4 was maintained for the reaction mixtures in each case, and this resulted in good quality crystals and high yield.

The physical properties for the two compounds showed that the two compounds were thermally stable up to $300^{\circ} \mathrm{C}$, after which the organic components starts decomposing. The elemental compositions for the two complexes were calculated based on the proposed structures. The solubility test in a wide spectrum of solvents (at room temperature) showed that the two compounds were insoluble in water, ethanol, DMF and DMSO.

The scanning electron micrographs of compounds I and II are presented in Fig. 1 and Fig. 2 respectively. The scale bar is about $50 \mu \mathrm{m}$. The SEM images revealed a greenish rectangular block for compound I and colourless square plate for compound II.

Table 1: Infrared Vibrational Frequencies for the Compounds I and II (All measurements are in $\mathrm{cm}^{-1}$ )

\begin{tabular}{|c|c|c|c|c|c|c|c|c|}
\hline Complexes & $v\left(\mathrm{H}_{2} \mathrm{O}\right)$ & $\begin{array}{l}\text { v(- } \\
\mathrm{N}-\mathrm{H})\end{array}$ & $\begin{array}{l}v(- \\
\text { coo) }\end{array}$ & $\begin{array}{l}v(\mathbf{P}- \\
0)\end{array}$ & $\begin{array}{l}\delta(\mathrm{P}- \\
0)\end{array}$ & $\begin{array}{l}v \text { (N- } \\
M)\end{array}$ & $\begin{array}{l}v(\mathbf{M}- \\
\mathrm{N})\end{array}$ & $\begin{array}{l}v(\mathbf{M}- \\
\text { O) }\end{array}$ \\
\hline$\left[\mathrm{CH}_{3} \mathrm{CH}_{2} \mathrm{NH}_{3}\right]_{2} \mathrm{Ni}_{3}\left(\mathrm{NH}_{3} \mathrm{C}_{6} \mathrm{H}_{4} \mathrm{CO}_{2}\right)_{2}\left(\mathrm{HPO}_{4}\right)_{4}\left(\mathrm{H}_{2} \mathrm{O}\right)_{2}$ & 3914 & 3401 & 1647 & 1108 & 936 & 2371 & 569 & 410 \\
\hline$\left[\mathrm{CH}_{3} \mathrm{CH}_{2} \mathrm{NH}_{3}\right]_{2} \mathrm{Zn}_{3}\left(\mathrm{NH}_{3} \mathrm{C}_{6} \mathrm{H}_{4} \mathrm{CO}_{2}\right)_{2}\left(\mathrm{HPO}_{4}\right)_{4}\left(\mathrm{H}_{2} \mathrm{O}\right)_{2}$ & 3926 & 3434 & 1644 & 1108 & 934 & 2377 & 606 & 435 \\
\hline
\end{tabular}

The infrared spectra of the complexes were recorded in the range of $4000-350 \mathrm{~cm}^{-1}$. The infrared spectrum showed the various vibrational modes expected for protonated amine, water molecule, metal- oxygen and metal-nitrogen bonds. The broad band at $3914 \mathrm{~cm}^{-1}$ (I) and $3926 \mathrm{~cm}^{-1}$ (II) is due to the presence of water molecule in the structure (Coates, 2000). The bands at 3542 and $3401 \mathrm{~cm}^{-1}$ (I) and $3434 \mathrm{~cm}^{-1}$ (II) are 
associated with stretching vibration of $\mathrm{NH}_{2}$ (Silverstein, Bassler and Morrill, 1981) and the band at $1647 \mathrm{~cm}^{-1}(\mathbf{I})$ and $1644 \mathrm{~cm}^{-1}$ (II) is attributed to the stretching vibration of COO group (Dong et al., 2011) indicating the involvement of oxygen atom of carboxyl group in bonding with the metal ion. The absorption band at $2371 \mathrm{~cm}^{-1}$ (I) and $2377 \mathrm{~cm}^{-1}$ (II) indicates that the Nitrogen atom of amino-group was coordinating to the metal (Badawi et al., 2007). The strong absorption bands at
1108 and $1014 \mathrm{~cm}^{-1}$ are associated with the asymmetric stretching vibration of $v(\mathrm{PO})$ groups whereas those at 936 and $629 \mathrm{~cm}^{-1}(\mathrm{I})$ and $934 \mathrm{~cm}^{-1}$ and $718 \mathrm{~cm}^{-1}$ (II) correspond to its bending mode (Ayi, 2006). The band at $569 \mathrm{~cm}^{-1}(\mathrm{I})$ and $606 \mathrm{~cm}^{-1}$ (II) is due to metal-nitrogen vibrations while the one at $410 \mathrm{~cm}^{-1}$ (I) and $435 \mathrm{~cm}^{-1}$ (II) is due to metal-oxygen vibrations.

Table 2: Percentage Yield and Elemental Composition of compounds I and II

\begin{tabular}{|c|c|c|c|c|c|c|c|}
\hline \multirow[t]{2}{*}{ Compounds } & \multirow{2}{*}{$\begin{array}{l}\% \\
\text { Yield }\end{array}$} & \multicolumn{6}{|c|}{ Elemental compositions (\%) } \\
\hline & & $\begin{array}{l}\text { Metal } \\
\text { Ion }\end{array}$ & $\mathbf{P}$ & C & $\mathbf{H}$ & $\mathbf{N}$ & 0 \\
\hline$\left[\mathrm{CH}_{3} \mathrm{CH}_{2} \mathrm{NH}_{3}\right]_{2} \mathrm{Ni}_{3}\left(\mathrm{NH}_{3} \mathrm{C}_{6} \mathrm{H}_{4} \mathrm{CO}_{2}\right)_{2}\left(\mathrm{HPO}_{4}\right)_{4}\left(\mathrm{H}_{2} \mathrm{O}\right)_{2}$ & 25.92 & $\begin{array}{l}\mathrm{Ni}= \\
18.31\end{array}$ & 12.89 & 22.45 & 3.95 & 5.82 & 36.59 \\
\hline$\left[\mathrm{CH}_{3} \mathrm{CH}_{2} \mathrm{NH}_{3}\right]_{2} \mathrm{Zn}_{3}\left(\mathrm{NH}_{3} \mathrm{C}_{6} \mathrm{H}_{4} \mathrm{CO}_{2}\right)_{2}\left(\mathrm{HPO}_{4}\right)_{4}\left(\mathrm{H}_{2} \mathrm{O}\right)_{2}$ & 39.21 & $\begin{array}{l}Z n= \\
20.00\end{array}$ & 12.63 & 22.00 & 3.87 & 5.76 & 35.84 \\
\hline
\end{tabular}

Table 2 shows the percentage yield and elemental compositions (obtained from the proposed structures) of the compounds I and II.

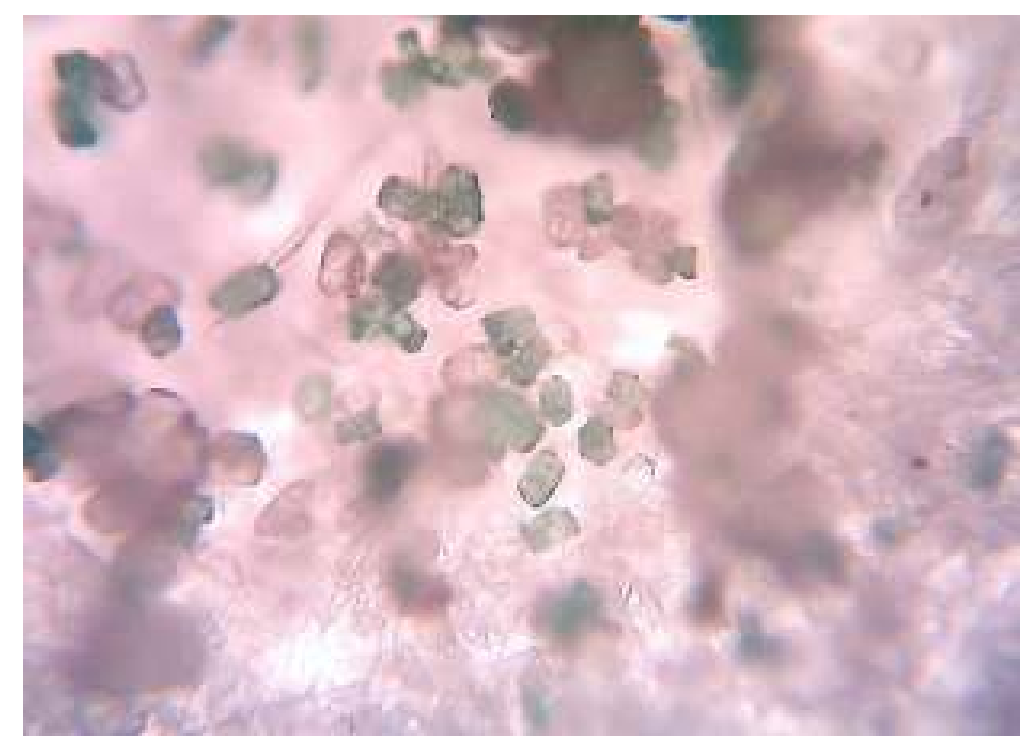

Fig. 1: SEM Image of $\left[\mathrm{CH}_{3} \mathrm{CH}_{2} \mathrm{NH}_{3}\right]_{2} \mathrm{Ni}_{3}\left(\mathrm{NH}_{3} \mathrm{C}_{6} \mathrm{H}_{4} \mathrm{CO}_{2}\right)_{2}\left(\mathrm{HPO}_{4}\right)_{4}\left(\mathrm{H}_{2} \mathrm{O}\right)_{2}$

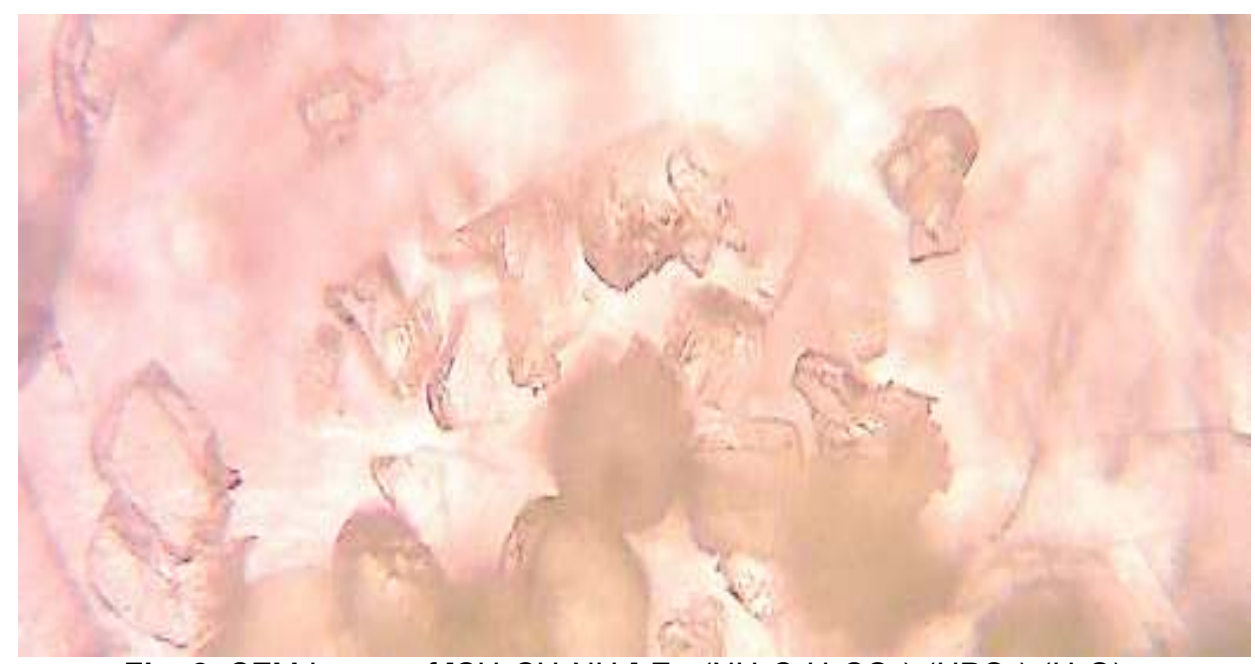

Fig. 2: SEM Image of $\left[\mathrm{CH}_{3} \mathrm{CH}_{2} \mathrm{NH}_{3}\right]_{2} \mathrm{Zn}_{3}\left(\mathrm{NH}_{3} \mathrm{C}_{6} \mathrm{H}_{4} \mathrm{CO}_{2}\right)_{2}\left(\mathrm{HPO}_{4}\right)_{4}\left(\mathrm{H}_{2} \mathrm{O}\right)_{2}$ 


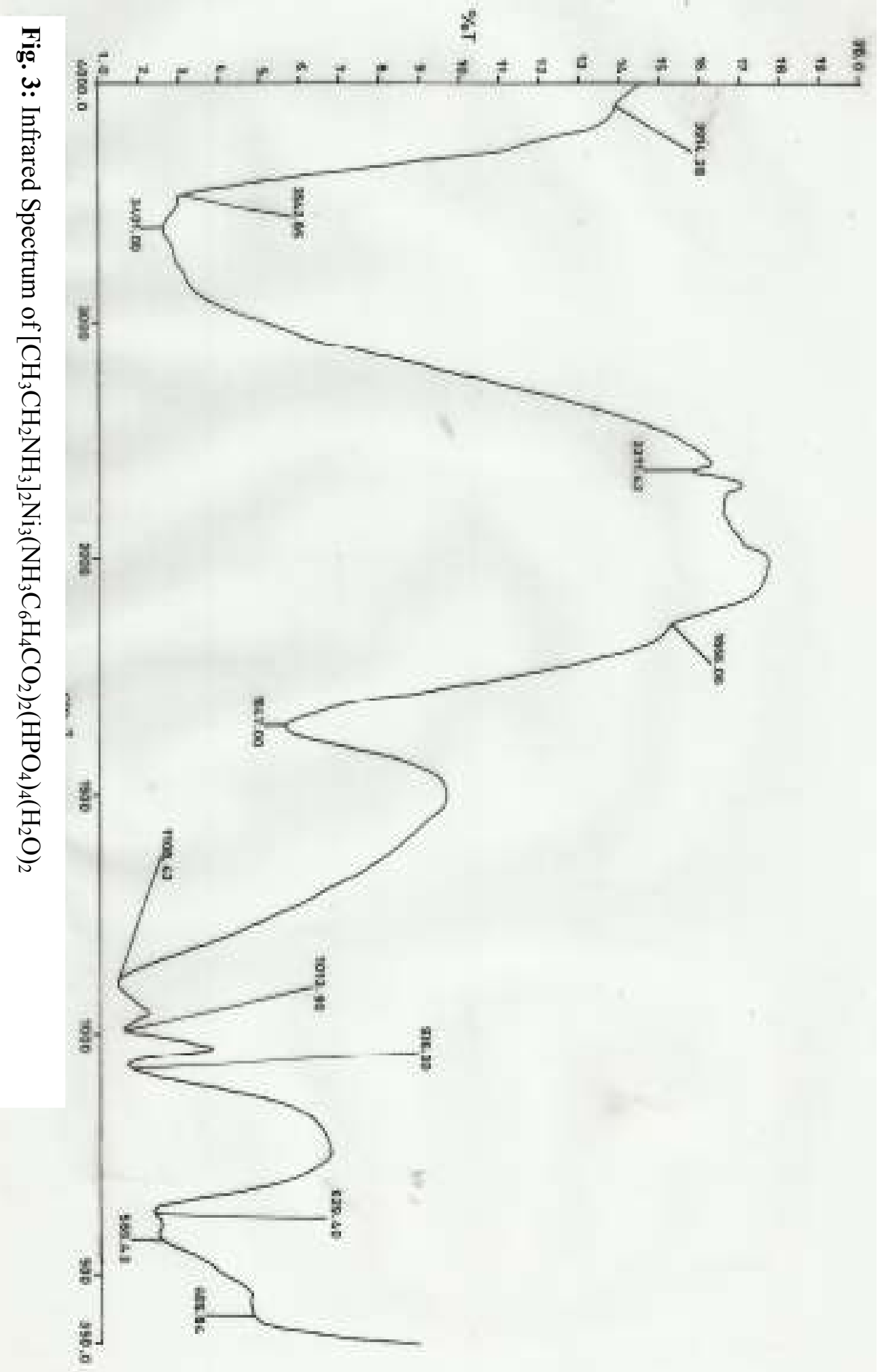




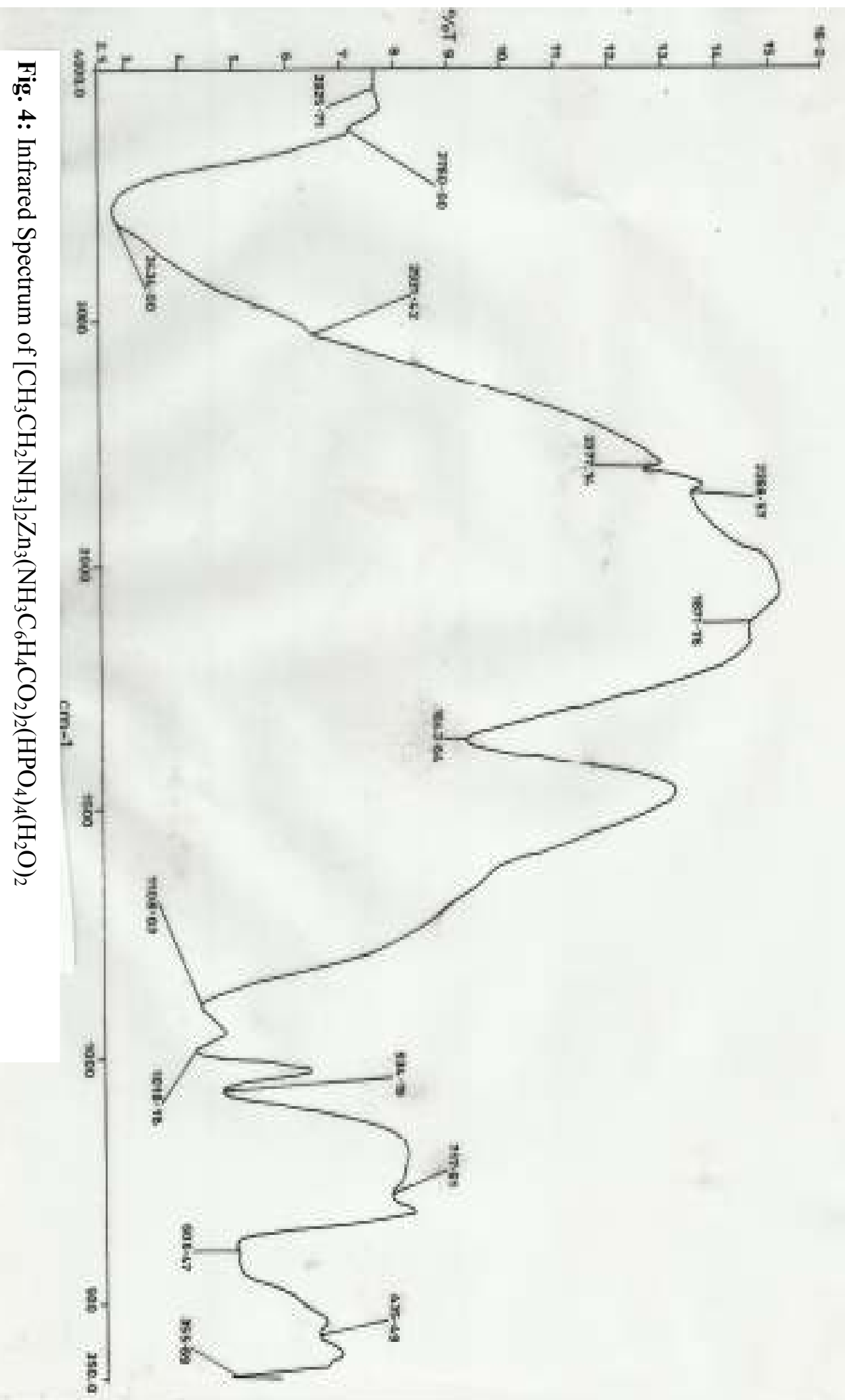




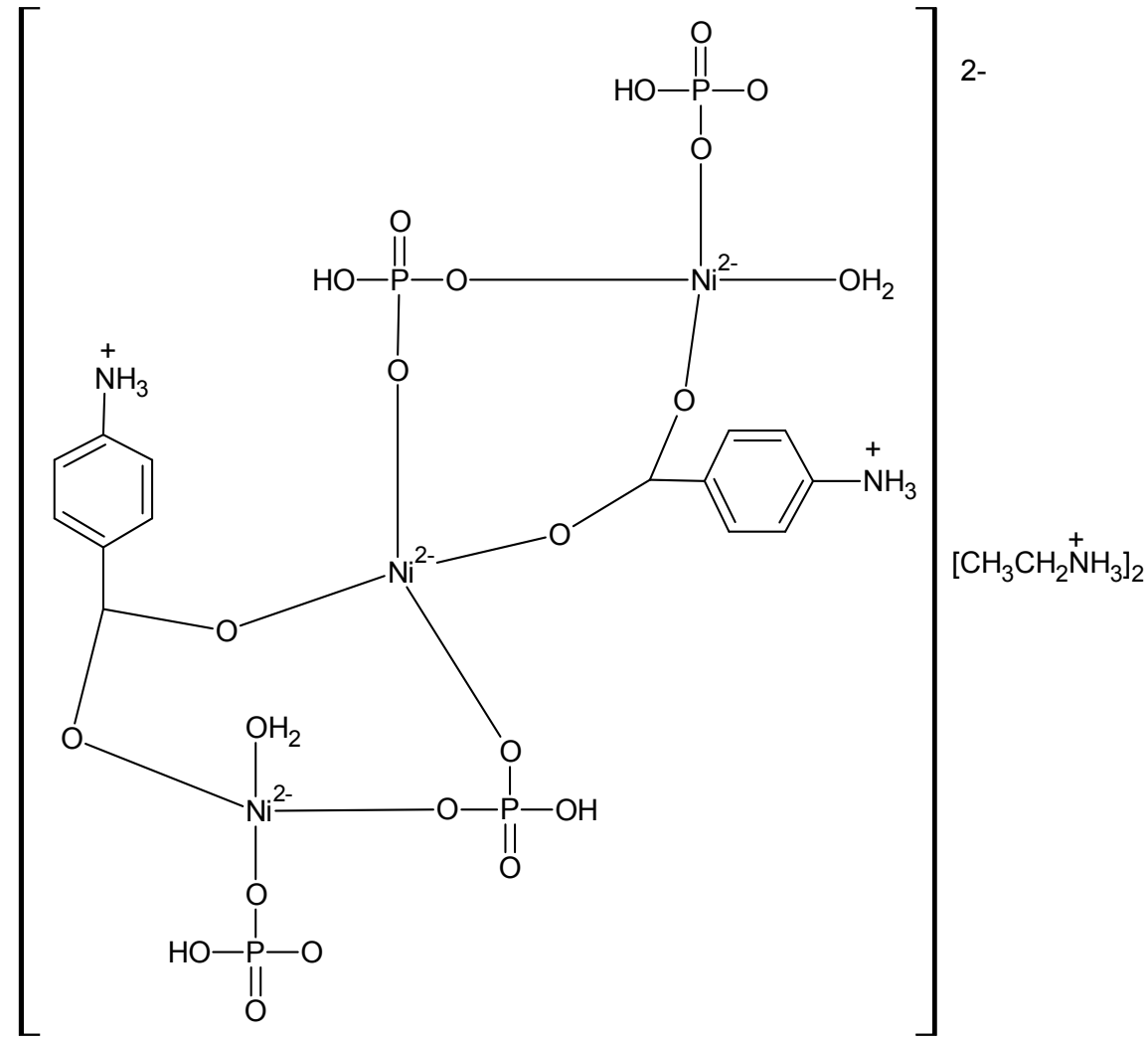

Fig. 5: Proposed structure of $\left[\mathrm{CH}_{3} \mathrm{CH}_{2} \mathrm{NH}_{3}\right]_{2} \mathrm{Ni}_{3}\left(\mathrm{NH}_{3} \mathrm{C}_{6} \mathrm{H}_{4} \mathrm{CO}_{2}\right)_{2}\left(\mathrm{HPO}_{4}\right)_{4}\left(\mathrm{H}_{2} \mathrm{O}\right)_{2}$

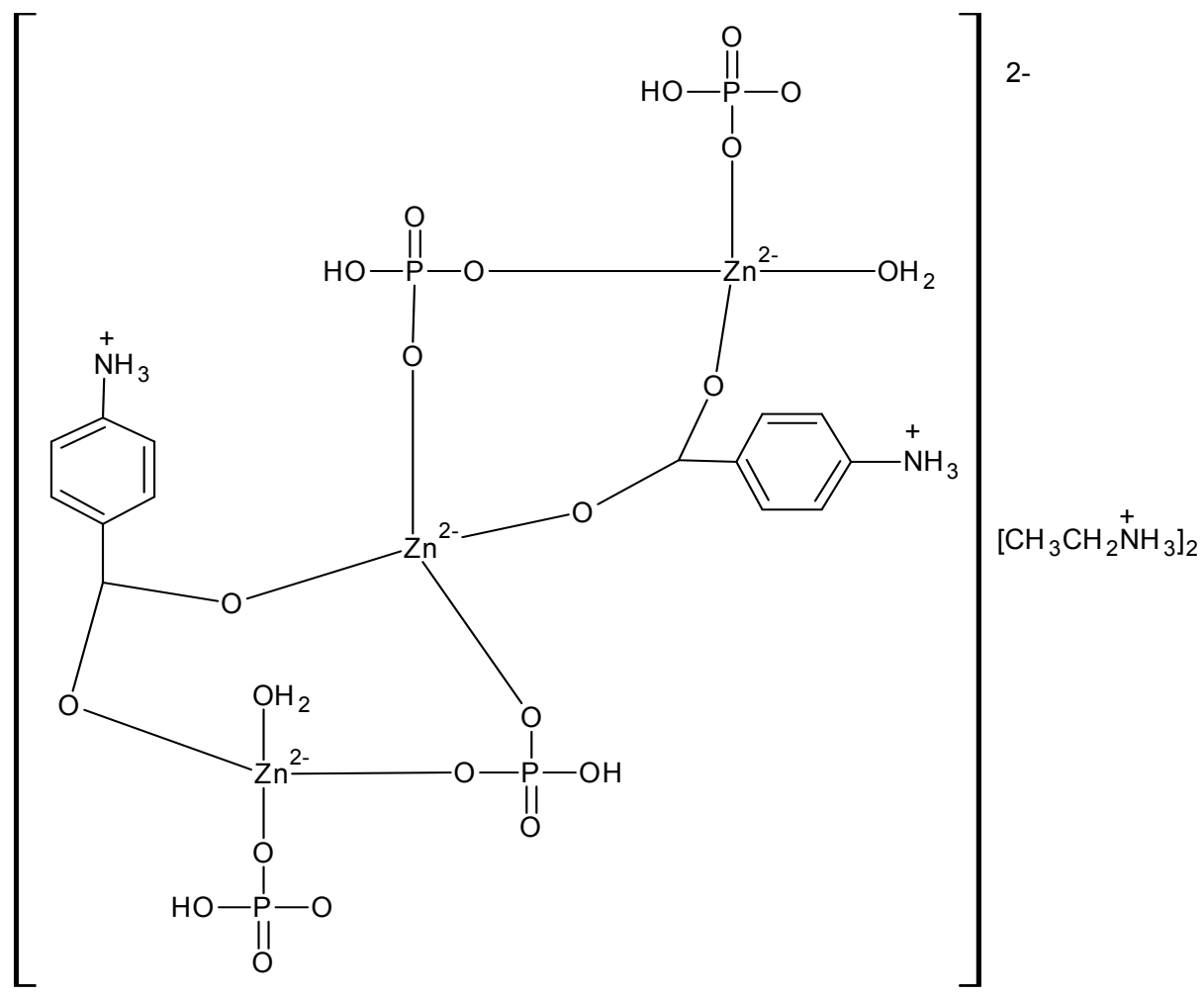

Fig. 6: Proposed structure of $\left[\mathrm{CH}_{3} \mathrm{CH}_{2} \mathrm{NH}_{3}\right]_{2} \mathrm{Zn}_{3}\left(\mathrm{NH}_{3} \mathrm{C}_{6} \mathrm{H}_{4} \mathrm{CO}_{2}\right)_{2}\left(\mathrm{HPO}_{4}\right)_{4}\left(\mathrm{H}_{2} \mathrm{O}\right)_{2}$ 


\section{CONCLUSIONS}

Using hydrothermal method, two aminetemplated metal phosphate frameworks have been synthesized. The IR spectra clearly showed the presence of water molecules in the complexes and terminals $\mathrm{NH}_{2}$ which could be used as linkers to form a network of different topologies. Also, the complexes were insoluble in water, ethanol, DMF and DMSO and thermally stable at $300^{\circ} \mathrm{C}$. This shows that the complexes could retain their structures at extreme conditions and this is one of the properties of a MOF material.

\section{ACKNOWLEDGEMENT}

This work has been supported by Dr. Ayi A. Ayi, the Head of Department of the Department of Pure and Applied Chemistry, University of Calabar. I must appreciate my co-researcher Mr. Samuel S. Etuk and also my family.

\section{REFERENCES}

Ayi, A. A., Burrows, A. D., Mahon, M. F and Pop, V. M., 2011. Sodium tri-hydrogen-1,4-Benzenediphosphonate: An Extended Coordination Network. Journal of Chemical Crystallography, (41): 1165 - 1168.

Ayi, A. A., Choudhury, A and Rao, C. N. R., 2005. A versatile route to hybrid open-framework materials. Global Journal of Pure and Applied Science, (11): $523-534$.

Ayi, A. A., 2006. A hybrid open-framework structure: Hydrothermal synthesis and characterization of Zinc (II) ethylaceto-acetate phosphate. International Journal of Natural and Applied Science, (1): $70-72$.

Badawi, A. M., Mohamed-Mekawis, A. S., Mohamed, M. $Z$ and Khowdiary, M. M., 2007. Surface and antitumor activity of some novel metal-based cationic surfactants. Journal of Cancer research and Therapeutics, (3): $198-206$.

Chen, X. H., Cao, Y. N., Zhang, H. H., Chen, Y. P.,

Chen, X. X and Chai, X. C., 2008. Hydrothermal synthesis and crystal structure of a new 3-D open framework Zinco-phosphate. Chinese Journal of Structural Chemistry, (27): $409-415$.

Clearfield, A and Demadis, K., 2012. The early History and Growth of Metal Phosphonate Chemistry. Chichester: John Wiley and Sons. pp. 1-41.

Coates, J., 2000. Interpretation of Infrared Spectra, A Practical Approach. Chichester: John Wiley and Sons. pp $10815-10837$.
Czaja, A. U., Trukhan, N and Muller, U., 2009. Industrial applications of metal-organic frameworks. Chemical Society Reviews, (38): $1284-1293$.

Dong, Z., Yan, Y., Zheng, R., Liu, D., Li, J., Han, Z and $\mathrm{Yu}$, J., 2011. Ionothermal Synthesis and Phase Transformation of Organic-inorganic Hybrid Neutral Zincophosphate Cluster $\left[\mathrm{Zn}\left(\mathrm{HPO}_{4}\right)\left(\mathrm{H}_{2} \mathrm{PO}_{4}\right)\right]\left[\mathrm{C}_{6} \mathrm{H}_{10} \mathrm{~N}_{3} \mathrm{O}_{2}\right]$. Chemical Research of Chinese Universities, (27): 531535.

Halper, S. R., Do, L., Stork, J. R and Cohen, S. M., 2006. Topological Control in Heterometallic Metalorganic frameworks by Anion Templating and Metalloligand Design. Journal of American Chemical Society, (128): 15255 - 15268.

Kitagawa, S., Kitaura, R and Noro, S., 2004. Functional Porous Coordination Polymers. Angewandte Chemie International Edition, (43): 2334 - 2375.

Logar, N. Z., Rajic, N., Stojakovic, D., Golobic, A and Kaucic, V., 2005. Synthesis and single crystal structure analysis of a new layered zinc phosphate. Pure and Applied Chemistry, (77): 1707 - 1717.

Murugavel, R., Anantharaman, G., Krishnamurthy, D., Sathiyendiran, M and Walawalker, M. G., 2000. Extended Metal-Organic Solids based on Benzenepolycarboxylic and aminobenzoic acids. Proceedings of Indian Academic Sciences, (112): $273-290$.

Natarajan, S., Mandal, S., Mahata, P., Rao, V. K., Ramaswamy, P., Banerjee, A., Paul, A. K and Ramya, K. V., 2006. The use of hydrothermal methods in the synthesis of novel open-framework materials. Journal of Chemical Science, (118): $525-536$.

Rowsell, J. L. C. and Yaghi, O. M., 2004. Metal Organic Frameworks: A New Class of Porous Materials. Microporous and Mesoporous Material, (73): $3-14$.

Silverstein, R. M., Bassler, G. C and Morrill, T. C., 1981. Spectrometric Identification of Organic Compounds ( $4^{\text {th }}$ Edition). New York: John Wiley and Sons. 